\title{
VACSATC (VACCINE SAFETY: ATTITUDES, TRAINING AND COMMUNICATION): WHY SUCH A PROJECT?
}

\author{
M J Alvarez-Pasquín (malvarezp.gapm@salud.madrid.org) ${ }^{1}$, H Heijbel $^{2}$, J Yarwood ${ }^{3}$, P Van Damme ${ }^{4}$, VACSATC partners ${ }^{5}$ \\ 1. Madrilenian Heath Service, Area 2. Spanish Society of Family and Community Medicine, Madrid, Spain \\ 2. Swedish Institute for Infectious Disease Control, Solna, Sweden \\ 3. Department of Health, London, United Kingdom \\ 4. University of Antwerp, Antwerp, Belgium \\ 5. The VACSATC partners are listed at the end of the article
}

\begin{abstract}
The Vaccine safety: attitudes, training and communication (VACSATC) project was established in 2006 to study perceptions of immunisation and vaccine safety, to improve training of healthcare professionals on vaccine safety and to improve the availability of information on vaccine safety on the internet that adheres to good information practices. The three year project is funded by the European Commission's Directorate General for Health and Consumers and by the partners. The project complements the activities of the Vaccine Safety Net project and the Vaccine European New Integrated Collaboration Effort (VENICE) project.
\end{abstract}

\section{Background}

Vaccinations against life-threatening diseases are one of the greatest public health achievements in history. Literally millions of premature deaths have been prevented, and countless more children have been saved from disfiguring illness [1]. Though some risks are unavoidable when dealing with vaccines, the medical, social and economic benefits they confer have led countries in Europe to establish childhood vaccination programmes to stop the spread of preventable diseases. In some countries, the programmes are based on recommendations while in others childhood immunisations have been made mandatory $[2,3]$.

Today, however, vaccines are becoming a victim of their own successes. Many individuals have never witnessed the debilitating diseases against which vaccines protect, and this has led to complacency about necessary immunisations [1]. The risk of side effects of medicinal products - and therefore also of vaccines are often not effectively communicated to the public, media and healthcare professionals. Especially the relation between risks and benefits of vaccination and the risk of not being vaccinated are not communicated well, as is information on how the number and seriousness of side effects relate to the number of vaccines administered. Anti-vaccination sentiment is growing in many European countries, in large part due to the controversial and hotly disputed link between immunisation and autism, between Hepatitis $B$ vaccination and multiple sclerosis in France, and between sudden death and convulsions and human papillomavirus immunisation in Austria, Germany, Spain and other countries, despite a lack of evidence for such a causal relationship.
The results of many surveys on attitudes to immunisation demonstrate that mothers believe that the measles, mumps, rubella (MMR) vaccine protects against diseases that are not serious. The surveys have also shown that MMR is the vaccine least likely to be considered safe [4-10]. On the other hand a study by Smith et al. published in 2007 found that the proportion of parents in the United Kingdom (UK) who believe the MMR vaccine to be a greater risk than the diseases against which it protects had fallen from $24 \%$ to $14 \%$ since 2002 . The proportion of people in that study in the UK who rejected vaccination completely remained stable in 2006 at just $6 \%$ [11]. The most significant finding from this latest survey is that there was a gradual and sustained increase in the proportion of parents who considered that the MMR vaccine was completely safe or posed just a slight risk, from 60\% in 2002 to $74 \%$ in 2006 . Clearly parents in the UK are not sure about the safety of the vaccine and the danger posed by the diseases that it protects against [11]. Not much is known about the situation in other countries and how it is changing.

The consequences of low vaccination coverage are serious not only for unvaccinated children, but also for society as a whole. 'Herd immunity' (a critical proportion of the population being immune to a particular infection that is spread from person to person, so that natural transmission of the infection is effectively inhibited) is threatened, and outbreaks of diseases reoccur that were thought to be under control [12]. The decision-making process regarding childhood immunisation is complex. Parents require information that is up to date, tailored to their individual needs and provided by health professionals who are well informed [13]. The role of well-trained healthcare staff in giving advice and an opportunity to discuss vaccination with concerned parents cannot be overemphasised $[11,14]$.

Given the impact of concerns about vaccine safety on vaccine coverage, the issue needs to be addressed by healthcare professionals offering vaccines [9]. Primary care physicians, paediatricians, family doctors, nurses and midwives as the most common contact points between parents and the immunisation delivery system, are most likely to be exposed to parental concerns about vaccine safety and have an important role to play in providing parents with balanced advice on this topic $[10,15,16]$. Physicians, 
nurses, midwifes and other healthcare professionals should increase their efforts to build honest and respectful relationships with patients, especially when parents express concerns about vaccine safety or have misconceptions about the benefits and risks of vaccination $[17,18]$. Medical and paramedical students should therefore receive adequate pre-service training in vaccinology already at the level of nursing schools and universities, although other strategies could be used in the post-graduate period (training, reminder/recall interventions, incentives, etc.).

Not only healthcare professionals but also school personnel trained in vaccine safety may serve as a valuable source of vaccine information for parents. Public information campaigns [19] and the use of mobile teams [20] also play a role in disseminating reliable information on vaccines. Among the factors influencing individuals' perception of vaccines are religious and philosophical beliefs, freedom of choice and individualism, as well as misinformation and over-perception of risk $[1,10,21,22]$.

The context in which patients search for health information has changed dramatically with the growth of the internet, progress in telemedicine, and changes in the coverage of health issues in the media. Increasingly, individuals search for information online before talking with their physician [23]. Although the precise effect of increasing use of the internet for health information is unclear, it seems that the internet worsens fears regarding vaccination safety. Anti-vaccination sites express a range of concerns related to vaccine safety, relying heavily on emotional appeal to convey their messages [24]. The most common characteristic of vaccinecritical websites is the inclusion of statements linking vaccinations with specific adverse events, especially idiopathic chronic diseases such as multiple sclerosis, autism, and diabetes [25]. Sites with factual refutation strategies alone are unlikely to counter the highly rhetorical appeals of such sites [26].

\section{Responding to the needs of improved information on immunisations}

Recognising the need of web-based information that is objective and based on science, the World Health Organization (WHO) Global Advisory Committee on Vaccine Safety established the Vaccine Safety Net Project in 2003. The project has developed criteria for good quality websites. Websites are evaluated and those that meet the criteria in content and credibility are listed on the WHO website at http://www.who.int/immunization_safety/safety_quality/ vaccine_safety_websites/en/index.html.

The need for good training of healthcare personnel has also been recognised by $\mathrm{WHO}$ and educational material has been made available at http://www.who.int/immunization_safety/.

Another initiative to improve training is the tutorial "Addressing Parents Concerns About Childhood Immunizations: A Tutorial for Primary Care Providers", developed by B. Levi (Penn State College of Medicine in the United States). This tutorial has the potential to enhance communication between parents and primary healthcare providers and, more generally, to improve clinicians' response to the growing resistance toward routine childhood immunisations [27].

In Europe, training materials have been produced as well, such as: the brochure "Argumentarium: Kinder impfen? Ja! Wieso?" ("Argumentarium: Vaccinating children? Yes! Why?") in Switzerland (http://www.bag.admin.ch/shop/00047/00140/index. html?lang=de), an Immunization Update Net by Junta de Andalucía in Spain (http://www.juntadeandalucia.es/salud/andaluciaessalud/ bolet/portada.asp?id=14), and a complete document about immunisation learning standards "National Minimum Standards for Immunisation Training" in the UK, which offers a wide range of information (http://www.hpa.org.uk/web/HPAwebFile/ HPAweb_C/1196942164323).

\section{The Vaccine safety: attitudes, training and communication (VACSATC) project}

The Vaccine safety, attitudes, training and communication (VACSATC) project (www.vacsatc.eu) was established in 2006 to study perceptions of immunisation and vaccine safety, to improve training of healthcare professionals regarding vaccine safety and to improve the availability of information on vaccine safety on the internet which adheres to good information practices. The project, funded by the European Commission's Directorate General for Health and Consumers and by the partners in the project, will run for three years. The project complements the activities of WHO and the Vaccine European New Integrated Collaboration Effort (VENICE) project (http://venice.cineca.org/the_project.html) coordinated by the Istituto Superiore di Sanitá in Rome.

The reasons for establishing the VACSATC project were:

- The infectious agents as well as rumours and concerns about vaccine safety cross country borders. The problems cannot be resolved by action in a single country.

- Further improvements could be made through sharing of experiences in different countries, for instance on risk communication, perception of the population's attitudes regarding vaccines, etc.

- The participation of centres of excellence will lead to improved quality and rapid dissemination of best practices, for example in training on immunisation, information about vaccines for the public, etc.

- Vaccine safety initiatives in individual countries are often inadequately funded [28].

The activities of the project are divided into work packages (WP). The objectives of three of them are given below:

WP5: To collect and summarise published material on perceptions of vaccination and carry out pilot and full scale studies on attitudes and perception,

WP6: To improve immunisation training for medical and paramedical personnel.

WP7: To increase the number of websites with information on vaccine safety and the number of websites that meet the WHO Vaccine Safety Net criteria for good information practices.

These three work packages use the same approach, namely to review the current status of the three aspects, attitudes, training and communication about immunisation, to share the expertise in partner organisations in order to develop a tool kit of best practices and to implement improvements at national level.

WP 5 is concerned with attitudes to vaccine-preventable diseases, immunisations and adverse events following immunisation (AEFI). At the beginning of the project, participants were invited to share studies on the subject, and at the same time the UK Department of Health performed a literature search. The number of good quality 
studies in the published literature was limited. Partners were also asked to identify studies in their own countries that examined attitudes to vaccine-preventable diseases, immunisations and AEFI. The main purpose was to describe the work already done and to gain a better understanding of parental attitudes across Europe. A secondary aim was to explore the possibility of developing a common approach for the participating countries. Thirty papers were assessed and emerging issues noted. Twenty-eight papers focused on childhood immunisations and the remaining two focused on high-risk groups above the age of 65 years who refused influenza immunisation. The main practical conclusions arising from this review were that the level of investigation into parental attitudes varies widely from country to country and that such approaches are not well developed: There was no common methodology to investigate the parental attitudes. Financial resources and number of staff available for this kind of research vary widely across the participating countries. The participants agreed on ten themes for future questionnaires that can be used to prepare questionnaires locally.

WP6 focuses on training on immunisation including vaccine safety and communication on vaccination. At the kick-off meeting in Lund, Sweden, in October 2006 it was agreed that due to the diversity of the healthcare systems, a definition of target groups in the participating countries was needed: Who immunises and who provides information on immunisation? In February 2007, a 'Setting the scene' questionnaire was drafted and distributed to the participating countries. One conclusion of the 'Setting the scene' phase was the necessity to improve the training on immunisation, and a strategy and tool were developed to evaluate the current training in immunisation and vaccine safety, addressed to curriculum managers and students at medical universities and nursing schools. As vaccinology is poorly addressed during the training of future healthcare workers although immunisation is a responsibility of all healthcare workers, an international vaccination course will be offered to medical, nursing and midwifery students in summer 2009 at the University of Antwerp (Belgium) that probably will be repeated every year. (see: http://www.ua.ac.be/main.aspx?c=. CEVSUMMERSCHOOL\&n=71545). A set of common criteria for good training in immunisation and vaccine safety will be identified by the end of the project.

The aim of WP7 is to improve dissemination of information on vaccine safety on the websites of the partner organisation and to increase the number of websites that meet the quality criteria of Vaccine Safety Net. An assessment of the partners' websites has been carried out. Documents on best practices and a webbased "library" have been developed in http://www.vacsatc.eu/ LibraryWindow.aspx. There are now 16 websites in Europe that are certified by the WHO Vaccine Safety Net Project.

The VACSATC project started with 16 partners in 14 countries. Subsequently, a further five partners from four different institutions started collaborating with the project. Plans to expand the work and the number of partners are on the way.

\section{Aknowledgements}

We thank Alison Brunier (World Health Organization, Switzerland) for her support on the work of websites development and advice.

\section{VACSATC partners:}

FN Aksakal (Gazi University Faculty of Medicine, Department of Public Health, Turkey); S Andrén (Swedish Institute for Infectious Disease Control, Sweden); B Aronsson (Södersjukhuset AB, Sweden); E Augustynowitcz (National Institute of Hygiene, Poland); A Bechini (Department of Public Health, University of Florence, Italy); M Bejersten (Swedish Institute for Infectious Disease Control, Sweden); M Blennow (Södersjukhuset AB, Sweden); M Bergsaker (Norwegian Institute of Public Health, Norway); S Boccalini (Department of Public Health, University of Florence, Italy); P Bonanni (Department of Public Health, University of Florence, Italy); I Czumbel (National Center for Epidemiology, Hungary); C Fu (Swedish Institute for Infectious Disease Control, Sweden); TI Gerhardsen (World Health Organization Regional Office for Europe, Denmark); M Grgic-Vitek (Institute of Public Health, Slovenia); K Habersaat (World Health Organization Regional Office for Europe, Copenhagen); IL Haugen (Norwegian Institute of Public Health, Norway); N Kerbo (Health Protection Inspectorate, Estonia); A Kraigher (Institute of Public Health of the Republic of Slovenia); H Lundin (Department of Informatics, Lund University, Sweden); MA Mayer (Collegi Oficial de Metges de Barcelona, Spain); R Muchl (Federal Ministry of Health, Family and Youth, Austria), E Netterlid (Swedish Institute for Infectious Disease Control, Sweden); JA Navarro (Spanish Association of Vaccinology, Spain); H Nökleby (Norwegian Institute of Public Health, Norway); A Pistol (Institute of Public Health - Bucharest, Romania); H Pors Muniz (Norwegian Institute of Public Health, Norway); M Robinson (Department of Health, UK); A Stanescu (Institute of Public Health, Romania); P Stefanoff (National Institute of Hygiene, Poland); J Tuells (University of Alicante, Spain); $\mathrm{N}$ Vladimirova (National Center of Infectious and Parasitic Diseases, Bulgaria); A Vorsters (University of Antwerp, Belgium).

\section{References}

1. Calandrillo SP. Vanishing vaccinations: why are so many Americans opting out of vaccinating their children? Univ Mich J Law Reform. 2004;37(2):353-440.

2. Stampi S, Ricci R, Ruffilli I, Zanetti F. Compulsory and recommended vaccination in Italy: evaluation of coverage and non-compliance between 1998-2002 in Northern Italy. BMC Public Health. 2005;5(1):42.

3. Topuzoglu A, Ozaydin GA, Cali S, Cebeci D, Kalaca S, Harmanci H. Assessment of sociodemographic factors and socio-economic status affecting the coverage of compulsory and private immunization services in Istanbul, Turkey. Public Health. 2005;119(10):862-9.

4. Gerdes J, Thorsen T. So dangerous are not measles, mumps and rubella...A qualitative survey of causes of MMR vaccination refusal in the county of Vejle. Ugeskr Laeger. 2006;168(33):2670-4. [In Danish].

5. Hilton S, Petticrew M, Hunt K. Parents' champions vs. vested interests: who do parents believe about MMR? A qualitative study. BMC Public Health. 2007;7:42.

6. Hilton S, Hunt K, Petticrew M. MMR: marginalised, misrepresented and rejected? Autism: a focus group study. Arch Dis Child. 2007;92(4):322-7.

7. Zucs AP, Crispin A, Eckl E, Weitkunat R, Schlipkoter U. Risk factors for undervaccination against measles in a large sample of preschool children from rural Bavaria. Infection. 2004;32(3):127-33.

8. Rotily M, Guagliardo V, Fontaine D, Garros B, Mayer C, Arrighi J, et al. Evaluation of measles, mumps and rubella vaccine coverage in 3 year old children in twelve French counties. Time-trends and related factors. Rev Epidemiol Sante Publique. 2001;49(4):331-41. [In French].

9. Carrasco-Garrido P, Gil de Miguel A, Hernández Barrera V, Vázquez-Fernández del Pozo S, Jiménez-Trujillo I, Jiménez-García R. Spanish parents' knowledge about vaccination in their children in the decade 1993-2003. Data by autonomous communities. Vacunas. 2006;4:144-50. [In Spanish].

10. Alfredsson R, Svensson E, Trollfors B, Borres MP. Why do parents hesitate to vaccinate their children against measles, mumps and rubella? Acta Paediatr 2004;93(9):1232-7.

11. Smith A, Yarwood J, Salisbury DM. Tracking mothers' attitudes to MMR immunisation 1996-2006.Vaccine. 2007;25(20):3996-4002.

12. Muscat M, Glismann S, Bang H. Measles in Europe in 2001-2002. Euro Surveill. 2003;8(6):pij=414. Available online: http://www.eurosurveillance.org/ ViewArticle.aspx?ArticleId $=414$

13. Smailbegovic MS, Laing GJ, Bedford H. Why do parents decide against immunization? The effect of health beliefs and health professionals. Child Care Health Dev. 2003;29(4):303-11. 
14. Dannetun E, Tegnell A, Hermansson G, Giesecke J. Parents' reported reasons for avoiding MMR vaccination. A telephone survey. Scand J Prim Health Care. 2005;23(3):149-53.

15. Freed GL, Clark SJ, Hibbs BF, Santoli JM. Parental vaccine safety concerns The experiences of pediatricians and family physicians. Am J Prev Med. 2004;26(1):11-4.

16. Hansen LF. The knowledge about measles, mumps and rubella among parents in the county of Roskilde. Ugeskr Laeger. 2002;164(49):5748-52.

17. Smith PJ, Kennedy AM, Wooten K, Gust DA, Pickering LK. Association between health care providers' influence on parents who have concerns about vaccine safety and vaccination coverage. Pediatrics. 2006;118(5):e1287-92.

18. Casiday R, Cresswell T, Wilson D, Panter-Brick C. A survey of UK parental attitudes to the MMR vaccine and trust in medical authority. Vaccine. 2006;24(2):177-84. Vaccine. 2006 Jan 12;24(2):177-84.

19. Salmon DA, Moulton LH, Omer SB, Chace LM, Klassen A, Talebian P, et al Knowledge, attitudes, and beliefs of school nurses and personnel and associations with nonmedical immunization exemptions. Pediatrics. 2004;113(6):e552-9.

20. Harmanci H, Gürbüz Y, Torun SD, Tümerdem N, Ertürk T. Reasons for nonvaccination during national immunization days: a case study in Istanbul, Turkey. Public Health. 2003;117(1):54-61.

21. Bonanni P, Bergamini M. Factors influencing vaccine uptake in Italy. Vaccine. 2001;20 Suppl 1:S8-12.

22. Torun SD, Bakirci N. Vaccination coverage and reasons for non-vaccination in a district of Istanbul. BMC Public Health. 2006;6:125.

23. Hesse BW, Nelson DE, Kreps GL, Croyle RT, Arora NK, Rimer BK, et al. Trust and sources of health information: the impact of the Internet and its implications for health care providers: findings from the first Health Information National Trends Survey. Arch Intern Med. 2005;165(22):2618-24.

24. Wolfe RM, Sharp LK, Lipsky MS. Content and design attributes of antivaccination web sites. JAMA. 2002;287(24):3245-8.

25. Zimmerman RK, Wolfe RM, Fox DE, Fox JR, Nowalk MP, Troy JA, et al. Vaccine criticism on the World Wide Web. J Med Internet Res. 2005;7(2):e17.

26. Davies P, Chapman S, Leask J. Antivaccination activists on the World Wide Web. Arch Dis Child. 2002;87(1):22-5.

27. Levi BH. Addressing Parents' Concerns About Childhood Immunizations: A Tutorial for Primary Care Providers. Pediatrics. 2007;120(1):18-26.

28. Directorate General for Health and Consumers. VACSATC: Vaccine Safety: attitudes, training and communication. Brussels: European Commission; Available from: http://ec.europa.eu/health/ph_projects/2005/action2/ action2 2005 3 en.htm

This article was published on 23 April 2009

Citation style for this article: Alvarez-Pasquín MJ, Heijbel H, Yarwood J, Van Damme P, VACSATC partners. VACSATC (Vaccine safety: attitudes, training and communication): Why such a project?. Euro Surveill. 2009;14(16):pii=19181. Available online: http://www. eurosurveillance.org/ViewArticle.aspx?ArticleId=19181 